This is an electronic reprint of the original article. This reprint may differ from the original in pagination and typographic detail.

Author(s): Lahti, Riikka; Bergna, Davide; Romar, Henrik; Hu, Tao; Comazzi, Alberto; Pirola, Carlo; Bianchi, Claudia L.; Lassi, Ulla

Title: Characterization of Cobalt Catalysts on Biomass-Derived Carbon Supports

Year: $\quad 2017$

Version:

Please cite the original version:

Lahti, R., Bergna, D., Romar, H., Hu, T., Comazzi, A., Pirola, C., Bianchi, C. L., \& Lassi, U. (2017). Characterization of Cobalt Catalysts on Biomass-Derived Carbon Supports. Topics in Catalysis, 60(17-18), 1415-1428. https://doi.org/10.1007/s11244-017-0823z

All material supplied via JYX is protected by copyright and other intellectual property rights, and duplication or sale of all or part of any of the repository collections is not permitted, except that material may be duplicated by you for your research use or educational purposes in electronic or print form. You must obtain permission for any other use. Electronic or print copies may not be offered, whether for sale or otherwise to anyone who is not an authorised user. 


\section{Characterization of cobalt catalysts on biomass-derived carbon supports}

2

3

4

5

6

7

8

9

10

11
Riikka Lahti ${ }^{1,2,}{ }^{*}$, Davide Bergna ${ }^{1,2}$, Henrik Romar ${ }^{1,2}$, Tao $\mathrm{Hu}^{1}$, Alberto Comazzi ${ }^{3}$, Carlo Pirola ${ }^{3}$, Claudia L. Bianchi ${ }^{3}$, Ulla Lassi ${ }^{1,2}$

${ }^{1}$ University of Oulu, Research Unit of Sustainable Chemistry, P.O.Box 3000, FI-90014 University of Oulu, Finland

${ }^{2}$ University of Jyvaskyla, Kokkola University Consortium Chydenius, Applied Chemistry, P.O.Box 567, FI- 67101

Kokkola, Finland

${ }^{3}$ Università degli Studi di Milano, Dipartimento di Chimica, Via Golgi, 19 - 20133 Milano, Italy

*E-mail address: riikka.lahti@chydenius.fi

Cobalt catalysts are known to have a high activity and selectivity in the Fischer-Tropsch reaction converting synthesis gas to higher hydrocarbons $\left(C_{5+}\right)$. These catalysts have been supported by different porous materials. Porous carbon materials like activated carbon (AC) have physical and chemical surface properties that affect the preparation of supported metal catalysts and can easily be tailored.

In this study, AC was produced by carbonization and steam activation of lignin, a waste fraction from the Kraft pulping process. A series of Co/AC-catalysts was produced and characterized by several techniques. According to the results, tailored properties (high surface area, mesoporosity) were obtained for carbon supports. Further, ash content could be reduced by acid treatment. Co/AC-catalysts prepared by ultrasonic assisted impregnation have high metal dispersion (10.1\%). It was also observed that small metal particles were difficult to reduce, but acid $\left(\mathrm{HNO}_{3}\right)$ treatment has a positive effect on reduction temperatures.

Keywords: activated carbon, catalyst, characterization, cobalt, support 


\section{Introduction}

The sustainable catalytic conversion of renewable resources to chemicals and fuels is a rapidly growing field in research. Practically all fuels and over $85 \%$ of the chemicals coming out of petrochemical refineries have seen at least one catalytic conversion step in their production process. Conventional catalysts have been supported by a number of supports, such as $\mathrm{Al}_{2} \mathrm{O}_{3}, \mathrm{SiO}_{2}$, and $\mathrm{TiO}_{2}$. Many recent reviews deal with the advantages of carbon supports for the preparation of highly dispersed metal catalysts. Porous carbon materials like activated carbon (AC) have physical and chemical surface properties that can easily be such as a large surface area, the proper pore size distribution and acid-base characters on the surface that affect to the preparation of metal supported catalysts.[1-3]

Cobalt-based catalysts are known to have a high activity in the Fischer-Tropsch reaction (FT) converting synthesis gas into linear hydrocarbons and waxes and have low activity for the water gas shift reaction. Many studies have been done with different preparation methods, cobalt loading, and supports.[4-9] It has been found that the support materials have a significant role on the activity of the heterogeneous catalysts. However, a strong metal-support interaction between cobalt and conventional oxide supports $\left(\mathrm{Al}_{2} \mathrm{O}_{3}, \mathrm{SiO}_{2}\right.$, etc.) inhibits the formation of catalytically active high dispersed metal.[10,11] It is known that obtain optimal catalytic FT performance both high surface area and a well-developed porosity are very important for achieving a high dispersion of the active phase in the catalyst. Carbon materials, especially AC, has surface areas significantly higher than another conventional oxide catalyst supports increasing surface area and porosity of the carbon facilitates the loading of metal [12]. As a chemically inert material, carbon support can reduce the interaction with the cobalt species and increase the cobalt reducibility [13]. Advantageously carbon materials can be prepared from residual biomass and waste materials which is an attractive property for decreasing the so-called "carbon footprint" of a biomass transformation process [2]. Beside the high surface area carbon support also has many other advantages in the catalytic applications like tailored pore size distribution that can be modified for specific reactions, resistance to acidic or basic media, amphoteric character due to the presence of various oxygenated functional groups which enhances metal adsorption and catalyst dispersion, the structure that is stable at high temperatures, even above $700{ }^{\circ} \mathrm{C}$ (except in the 
presence of oxygen $>200{ }^{\circ} \mathrm{C}$ and for hydrogenation reactions $>400^{\circ} \mathrm{C}$ ), less expensive compared to alumina and silica supports; porous carbons can be prepared in different physical forms (granules, extrudates, pellets, fibers, cloths, etc.), hydrophobic carbon can be modified to increase the hydrophilicity and active phase can be recovered by eliminating the support through burning away the carbon. [2]

By modifying the carbon support, surface pore structure and functional groups $(\mathrm{O}, \mathrm{N}, \mathrm{H})$ supported Cocatalysts with a high degree of reduction and high Co dispersion can be obtained. These functional groups are considered anchoring sites for cobalt particles on the surface of AC, which can increase the cobalt metalloading, dispersion, and stability.[13] It has been observed that the more acidic the groups are, the less hydrophobic is the carbon surface, making the surface more accessible to the aqueous solution of the metal precursor upon impregnation. The metallic dispersion is said to increase with the increased amount of oxygen on the surface. Oxygen groups on the surface have been most studied since they are formed spontaneously by exposure of the material to the atmosphere during the activation process. The concentration of these groups can be increased with different oxygenation treatments such as nitric acid disposal. Fixation of the acidic groups on the surface of the AC makes the surface more hydrophilic, decreases its $\mathrm{pH}$, and increases the negative surface charge density. These treatments can also affect the surface area and pore texture of the activated carbons. $[12,14,15]$

Mesopore volume and mean mesopore size have been reported to be important parameters to control metal particle size and dispersion on carbon materials. A support with modified mesoporous and macroporous structure can have excellent advantages in FT reaction because larger pores benefits rapid molecular transportation and enhances the production for longer hydrocarbon chain distribution. The microporous structure of activated carbon is claimed to result in high methane and light hydrocarbon selectivity. $[13,16]$ A number of studies have been shown that addition of noble metals has a strong impact on the activity and selectivity on cobalt catalysts. The addition of noble metal promoters can shift the temperature needed to reduce cobalt oxide to metallic cobalt to lower temperatures, but its effect on the degree of reduction has been reported to be rather minor. Instead, the improved activity of noble metal promoted cobalt catalysts has been mainly attributed to higher cobalt dispersions. [17-19] 
Many activated carbons have reported having high ash content. Ash content has a relatively small, but significant negative effect on the adsorption of the metal precursor. By selecting an appropriate precursor and modifying the carbon with different treatments, it is possible to prepare porous carbons with very low ash content. [2, 3]

Preparation of carbon supported metal catalyst can be done with impregnation methods, precipitation methods or by ion-exchange method. With impregnation methods, incipient wetness method is performed in which the metal precursor is dissolved in small amount of solvent just enough to fill the pores of the support. Cobalt-based catalysts are relatively seldom prepared with precipitation methods but few papers have been published. [20-24]

In this study, a series of unpromoted and promoted cobalt catalysts supported on AC used as such or modified by different acid treatments have been prepared and characterized. Effect of acid pretreatments $(\mathrm{HCl}$ and $\mathrm{HNO}_{3}$ ) on $\mathrm{AC}$ and different preparation methods including impregnation methods and precipitation methods have been studied. Also, the effect of promoting the cobalt catalysts with noble metals ruthenium and rhenium have been tested in this study.

\section{Experimental}

\subsection{Preparation of activated carbon}

The lignin was dried and sieved to obtain particles of $0.8-1.2 \mathrm{~mm}$ in diameter. The sieved lignin was carbonized and steam activated in a one-step process in a rotating quartz reactor (Nabertherm GmbH RSRB 80). The thermal profile during the whole process was divided into two parts: the first carbonization step, in which the temperature was raised to $800^{\circ} \mathrm{C}$ with a ramp of $6.7^{\circ} \mathrm{C} / \mathrm{min}$, procured the total carbonization of the lignin followed by the activation step. During the activation temperature was kept at $800^{\circ} \mathrm{C}$ for $120 \mathrm{~min}$ with a stream of water steam $\left(120 \mathrm{~g} / \mathrm{h}\right.$ at $\left.140{ }^{\circ} \mathrm{C}\right)$, created the proper surface activation. During the whole process, the reactor was flushed with an inert gas, in ramping step only $\mathrm{N}_{2}$ (flow $200 \mathrm{ml} / \mathrm{min}$ ) and in activation step carrier gas $\left(\mathrm{N}_{2}\right.$ flow $\left.200 \mathrm{ml} / \mathrm{min}\right)$ and steam $\left(120 \mathrm{~g} / \mathrm{h}\right.$ at $\left.140{ }^{\circ} \mathrm{C}\right)$. The resulting $\mathrm{AC}$ was characterized for ash content, carbon content (TC), specific surface area, and pore size distribution. 


\subsection{Preparation of catalysts}

The formed AC was crushed and fractioned by sieving into particle size 50-100 $\mu \mathrm{m}$. Some of the carbon was used as such, other parts either acid-treated with hydrochloric acid $(\mathrm{HCl})$ in order to demineralize the sample or oxidized with nitric acid $\left(\mathrm{HNO}_{3}\right)$ in order to introduce functional groups into the carbon. Acid treatments were performed with 30 wt. $\% \mathrm{HCl}$ or with $10 \mathrm{wt} . \% \mathrm{HNO}_{3}$ refluxed $3 \mathrm{~h}$ and washed with distilled $\mathrm{H}_{2} \mathrm{O}$ until pH was neutral. Finally, the $\mathrm{AC}$ was dried overnight at $105^{\circ} \mathrm{C}$. AC demineralized with $\mathrm{HCl}$ was used as a support in the preparation of catalyst $\mathrm{AC}-\mathrm{HCl}-\mathrm{Co}-\mathrm{IW}$ and $\mathrm{AC}$ oxidized with $\mathrm{HNO}_{3}$ was used as a support in the preparation of catalysts $\mathrm{AC}-\mathrm{HNO}_{3}-\mathrm{Co}-\mathrm{IW}$. AC-Co-IW was prepared by incipient wetness impregnation of cobalt as such without any pretreatment of AC. Cobalt catalysts containing $10 \mathrm{wt}$. \% of Co were prepared by incipient wetness impregnation of the $\mathrm{ACs}$ using $\mathrm{Co}\left(\mathrm{NO}_{3}\right)_{3} * 6 \mathrm{H}_{2} \mathrm{O}$ as a precursor. Promoter metals ruthenium or rhenium were added in some catalysts using precursor metal salts $\mathrm{Ru}(\mathrm{NO})\left(\mathrm{NO}_{3}\right)_{3}(\mathrm{AC}-\mathrm{CoRu}-\mathrm{IW})$ or $\mathrm{ReO}_{4} \mathrm{H}$ (AC-CoRe-IW) in order to get 0.2 wt. \% promoter metal on the catalyst. Promoter metal was added to precursor solution and performed one-step incipient wetness impregnation. After impregnation, the catalysts were dried overnight at $105{ }^{\circ} \mathrm{C}$ and calcined at $320{ }^{\circ} \mathrm{C}$ for 16 hours. The calcination step was performed in a quartz reactor placed into a tubular oven and flushed with nitrogen $\left(240 \mathrm{ml} / \mathrm{h} / \mathrm{g}_{\text {cat }}\right)$ during the whole process. Beside incipient wetness impregnation method, precipitation method was used in the preparation of AC-Co-PR catalyst. The cobalt precursor $\mathrm{Co}\left(\mathrm{NO}_{3}\right)_{3} * 6 \mathrm{H}_{2} \mathrm{O}$ was dissolved in distilled $\mathrm{H}_{2} \mathrm{O}$ together with urea in a molar ratio of cobalt to urea of $1: 2$, and $\mathrm{AC}$. The resulting solution was heated to $80{ }^{\circ} \mathrm{C}$ and stirred overnight to precipitate the cobalt. Finally, the impregnated $\mathrm{AC}$ was dried overnight at $105^{\circ} \mathrm{C}$ before calcination. With catalyst AC-Co-US, ultrasonic assisted impregnation method was performed using an ultrasonic bath (VWR USC $200 \mathrm{TH}, 45 \mathrm{kHz}$ ) during the addition of precursor solution $\left(\mathrm{Co}\left(\mathrm{NO}_{3}\right)_{3} * 6 \mathrm{H}_{2} \mathrm{O}\right.$ dissolved in water) with a total US exposure time equal to $60 \mathrm{~min}$ at room temperature. After sonication, catalyst was rotated overnight in a rotating mixer (Rotavapor) and then dried overnight at $105^{\circ} \mathrm{C}$. The calcination step was performed in the same way for all catalysts as described above. A summary of the catalysts prepared and the preparation methods of Co/AC-catalysts are presented in Table 1 and Figure 1. 


\subsection{Catalyst characterization}

133

134

135

136

137

138

139

140

141

142

143

144

145

146

147

148

149

150

151

152

153

154

155

The resulting catalysts (see Table 1) were characterized by a number of methods including elemental analysis, nitrogen physisorption, ICP-OES, SEM, TEM, DRIFT, XPS, XRD, and TPR analysis.

\subsubsection{Total carbon and ash contents}

The percentage of total carbon present in prepared ACs was measured using Skalar Primacs MCS instrument. Dried samples were weighted in quartz crucibles, combusted at $1100{ }^{\circ} \mathrm{C}$ in a pure oxygen atmosphere and the formed $\mathrm{CO}_{2}$ was analyzed by an IR analyzer. The total mass of carbon in each sample was calculated as a percent of the mass initially weighted.

All samples were analyzed for ash content. A known amount of AC was transferred to tared crucibles and combusted in a muffle furnace for two hours at $815^{\circ} \mathrm{C}$ with an initial temperature ramp of $9{ }^{\circ} \mathrm{C} / \mathrm{min}$. The ash contents were calculated as a percent of the initial dried biomass.

\subsubsection{Surface areas and pore distribution}

Specific surface areas and pore size distributions were calculated from adsorption isotherms of $\mathrm{N}_{2}$ at isothermal conditions in liquid nitrogen according to the BET (Brunauer-Emmett-Teller) theory. Pore distribution was calculated from the adsorption isotherms using the BJH (Barrett-Joyner-Halenda) method. Each sample (about 100mg) was weight in a quartz tube. Samples were evacuated and heated in order to remove any adsorbed components and moisture. Evacuated samples were measured under isothermal conditions by Micromeritics ASAP 2020.

\subsubsection{Metal content, dispersions and particle sizes}

Metal contents of samples were measured by inductively coupled optical emission spectrometry (ICP-OES) using a Perkin Elmer Optima 5300 DV ICP-OES instrument. 0.10-0.12 g samples were added in 37 \% 
hydrochloric acid and $63 \%$ nitric acid, then digesting in a microwave oven (MARS, CEM Corporation) at 200

${ }^{\circ} \mathrm{C}$ for $10 \mathrm{~min}$. After digestion, the solution was diluted to $50 \mathrm{ml}$ and measured by ICP-OES.

Metal dispersions and particle sizes were measured from calcined samples by chemisorption of carbon monoxide (CO) assuming that stoichiometric ratio of was 1:1 between the adsorbent and cobalt (CO: $\mathrm{Co}$ ) [2526]. Each sample (about $500 \mathrm{mg}$ ) was weight in a U-shaped quartz tube and the sample was supported with glass wool. Prior to measurements, the sample was evacuated followed by a reduction in a stream of hydrogen $\left(\mathrm{H}_{2}\right)$ at $350^{\circ} \mathrm{C}$. Measurements were done using a Micromeritics ASAP 2020.

\subsubsection{Catalyst morphology}

A field emission scanning electron microscope (FESEM) Zeiss Ultra Plus equipped with and energy-dispersive X-ray spectroscopy (EDS) analysis system at the Center of Microscopy and Nanotechnology, University of Oulu was used to study the microstructure of the catalysts and for elemental analyses.

The morphology of the catalyst particles dispersed in the microemulsion was studied using an energy filtered transmission electron microscope EFTEM (LEO 912 OMEGA EFTEM). The catalysts samples were dispersed in acetone and pretreated in an ultrasonic bath for several minutes. A small drop of the microemulsion was deposited on a copper grid pre-coated with carbon and then evaporated in air at room temperature. The particle size of the samples was measured from TEM images of each sample and given in a reasonable range. The accelerating voltage and emission current in the measurements were $120 \mathrm{kV}$ and 8-15 $\mu \mathrm{A}$, respectively, while the resolution of the instrument was $0.37 \mathrm{~nm}$.

X-ray diffraction (XRD) patterns were recorded by a PANalytical X'Pert Pro X-ray diffraction equipment using monochromatic CuK $\alpha 1$ radiation $(\lambda=1.5406 \AA)$ at $45 \mathrm{kV}$ and $40 \mathrm{~mA}$. Diffractograms were collected in the $2 \theta$ range $5-80^{\circ}$ at $0.017^{\circ}$ intervals and with scan step time of $110 \mathrm{~s}$. The crystalline phases and structures were analyzed by HighScore Plus.

\subsubsection{Temperature programmed reduction and oxidation}


The conventional temperature programmed reduction experiments (TPR) were performed using a Thermoquest Mod. TPR/D/O 1100 (TCD detector) by feeding $30 \mathrm{ml} / \mathrm{min}$ of a 5.1\% v/v H2 in Ar gas mixture while heating by $8{ }^{\circ} \mathrm{C} / \mathrm{min}$ from $50^{\circ} \mathrm{C}$ up to $900^{\circ} \mathrm{C}$. The samples have been initially pre-treated in a flow of argon at $\mathrm{T}=200^{\circ} \mathrm{C}$ for $0.5 \mathrm{~h}$. The TPR profiles of the catalysts exhibit hydrogen consumption peaks attributed to two-step reduction of $\mathrm{CO}_{3} \mathrm{O}_{4}$ to metallic cobalt with intermediate phase consisting mainly of $\mathrm{CoO}$ but most likely other hard-reduced cobalt oxides are present in the second peak.

(1) $\mathrm{Co}_{3} \mathrm{O}_{4}+\mathrm{H}_{2} \rightarrow 3 \mathrm{CoO}+\mathrm{H}_{2} \mathrm{O}$

(2) $3 \mathrm{CoO}+3 \mathrm{H}_{2} \rightarrow 3 \mathrm{Co}^{0}+3 \mathrm{H}_{2} \mathrm{O}$

The degree of reduction for the catalysts was measured on a Micromeritics Autochem by reoxidation of reduced catalysts. Small portions, about $25 \mathrm{mg}$, of each catalyst were weighed into a quartz tube. Prior to analysis, the samples were dried at $100{ }^{\circ} \mathrm{C}$ for 1 hour and then reduced for 1 hour at $350{ }^{\circ} \mathrm{C}$ in a flow of $10 \%$ $\mathrm{H}_{2}$ in Ar according to reactions (1) and (2). Co surface was rinsed with He flow until the signal from the TCD detector returned to the baseline. Small pulses of oxygen ( $5 \%$ in $\mathrm{He}$ ) were added using a calibrated loop until signals with a constant area were obtained. Between the pulses, the signal was allowed to return to baseline before applying next pulse. The degree of reduction was calculated from the moles of oxygen consumed assuming that all $\mathrm{Co}^{0}$ was oxidized to $\mathrm{CO}_{3} \mathrm{O}_{4}$ according to reaction (3) compared to the amount of oxygen theoretically needed for a complete re-oxidation of $\mathrm{Co}^{0}$. Any oxidation of the promoter metals or other reductions/ oxidations of other Co-species were not considered in the calculations.

(3) $3 \mathrm{Co}^{0}+2 \mathrm{O}_{2} \rightarrow \mathrm{Co}_{3} \mathrm{O}_{4}$

\subsubsection{X-ray photoelectron spectroscopy}

X-ray photoelectron spectroscopy (XPS) analysis was performed using a Thermo Fisher Scientific ESCALAB 250Xi XPS System at the Center of Microscopy and Nanotechnology, University of Oulu (Finland). The catalyst samples were placed on an Indium film. With pass energy of $20 \mathrm{eV}$, the spot size of $900 \mu \mathrm{m}$, the accuracy of the reported binding energy was $\pm 0.2 \mathrm{eV}$. The $\mathrm{Al}, \mathrm{O}, \mathrm{Co}, \mathrm{Re}$ or $\mathrm{Ru}, \mathrm{C}, \mathrm{In}$ and $\mathrm{N}$ were measured for all samples. 
The measurement data were analyzed by Avantage V5. The monochromatic AlKa radiation (1486.7 eV) operated at $20 \mathrm{~mA}$ and $15 \mathrm{kV}$. Charge compensation was used to determine the presented spectra and the calibration of the binding energies (BE) were performed by applying the $\mathrm{C} 1 \mathrm{~s}$ line at $284.8 \mathrm{eV}$ as a reference.

\subsubsection{The Diffuse Reflectance Infrared Fourier Transform}

The Diffuse Reflectance Infrared Fourier Transform (DRIFT) analyses were performed by Brüker PMA 50 Vertex 80v equipment. In the DRIFT measurements the sample was maintained in a nitrogen flow at $105^{\circ} \mathrm{C}$ for $60 \mathrm{~min}$ for the removal of water, then the chamber was cooled down to $25^{\circ} \mathrm{C}$ in a nitrogen atmosphere, Analyses resolution was $4 \mathrm{~cm}^{-1}$ and 100 scans/min. Activated carbon samples were mixed with $\mathrm{KBr}(1: 300)$ in a mortar to obtain a homogenous powder.

\section{Results and discussion}

\subsection{Characterization results}

Characterization results of untreated and treated samples are presented in Table 2. The table presents surface areas, pore sizes, pore volumes, and distributions. Also, total carbon content and ash contents are presented in Table 2. According to these analyses, carbonization and steam activation increased the carbon content of the Kraft lignin remarkable. Surface area (see Table 2) increased from 4.6 to $810 \mathrm{~m}^{2} / \mathrm{g}$ and carbon content from 65 to $96 \%$. According to ash content, treatment with acid removed ash/minerals from the AC. Treatment with $\mathrm{HCl}$ seemed to remove some ash (from 6.1 to $4.8 \%$ ) and treatment with $\mathrm{HNO}_{3}$ removed all remaining (from 6.1 to $0.0 \%$ ) ash from the $\mathrm{AC} . \mathrm{HNO}_{3}$ treatment seemed to collapse some of the carbon structure observed from decreasing surface area, pore volume, and total carbon content. Instead, $\mathrm{HCl}$ treatment seemed to open some of the carbon pore structure that could be seen from the slight increase in BET surface area.

The surface area of AC produced from Kraft lignin was rather high, $810 \mathrm{~m}^{2} / \mathrm{g}$, (see Table 2) compared to conventionally used supports which surface area is approximately $200 \mathrm{~m}^{2} / \mathrm{g}$ or less [27-29]. Pore distribution 
according to BJH model of AC (see Table 2) was $32 \%$ of micropores (diameter smaller than $2 \mathrm{~nm}$ ), $62 \%$ of mesopores (diameter from $2 \mathrm{~nm}$ to $50 \mathrm{~nm}$ ) and $6 \%$ of macropores (diameter larger than $50 \mathrm{~nm}$ ).

Elemental analysis ( $\mathrm{C}, \mathrm{H}, \mathrm{O}, \mathrm{N})$ was performed for activated carbon samples before $\mathrm{Co}$ addition and a summary of these results is presented in Table 3. Results from the elemental analysis showed that treatments with acid $\mathrm{HNO}_{3}$ and $\mathrm{HCl}$ increased the amount of hydrogen in the carbon support. Treatment with $\mathrm{HNO}_{3}$ increased nitrogen content in the AC support but the amount of oxygen decreased to zero. According to the literature, treatment with $\mathrm{HNO}_{3}$ will increase oxygen at the carbon surface. In the results obtained from the elementary analyses, no such increase could be measured.

Surface area, pore volume, pore size, cobalt metal dispersion, metal particle size and metal surface area of prepared and calcined Co/AC-catalysts are presented in Table 4. Impregnation with metal precursor decreased the BET surface area about $10-26 \%$ within range $A C-\mathrm{HNO}_{3}-\mathrm{Co}-\mathrm{IW}<\mathrm{AC}-\mathrm{Co}-\mathrm{IW}<\mathrm{AC}-\mathrm{Co}-\mathrm{PR}<\mathrm{AC}$ CoRe-IW $<$ AC-CoRu-IW $<$ AC-HCl-Co-IW $<$ AC-Co-US. Pore volumes decreased about 10-32 \% within range AC$\mathrm{HNO}_{3}$-Co-IW $<$ AC-Co-IW $<$ AC-Co-PR $<$ AC-CoRu-IW $<$ AC-CoRe-IW $<$ AC-HCl-Co-IW $<$ AC-Co-US. With catalyst ACCo-US and AC-HCl-Co-IW, the BET surface areas and pore volumes decreased most (BET surface areas $26 \%$ and pore volumes $32-27 \%$ ). Since the decrease of the surface areas and pore volumes were in some cases quite high it seems an indication to that there might be some other compounds involved for example nitrates from the precursor. Also, there is a possibility that some treatments e.g. US might collapse some of the AC surface structure.

According to CO-chemisorption results dispersion of cobalt ranged from $0.7-10.1 \%$ (see Table 4) within range AC-HCl-Co-IW $<$ AC-CoRu-IW $<$ AC-HNO ${ }_{3}-\mathrm{Co}-\mathrm{IW}<\mathrm{AC}-\mathrm{CoRe}-\mathrm{IW}<\mathrm{AC}-\mathrm{Co}-\mathrm{IW}<\mathrm{AC}-\mathrm{Co}-\mathrm{US}$. Compared to previous studies [29] with conventional supported $\left(\mathrm{Al}_{2} \mathrm{O}_{3}, \mathrm{SiC}, \mathrm{TiO}_{2}\right)$ cobalt dispersion in Co/AC-catalysts was quite competitive and in some cases rather high, especially with catalyst AC-Co-US dispersion of Co was even high as $10.1 \%$. Also, catalyst AC-Co-IW gave quite high values for the dispersion of cobalt metal, $8.6 \%$. Otherwise, it was expected, and as it was discussed in introduction part that oxidation treatment leads to a higher dispersion; treatment with $\mathrm{HNO}_{3}$ did not lead any particularly high cobalt dispersion on the surface and the 
metal dispersion of catalyst $\mathrm{AC}-\mathrm{HNO}_{3}-\mathrm{Co}-\mathrm{IW}$ was $3.4 \%$. The reason for this might be that treatment with $\mathrm{HNO}_{3}$ did not increase the oxygen content of the $\mathrm{AC}$. Instead, treatment with $\mathrm{HCl}$ increased oxygen content in the AC (see Table 3) but also in this case no higher metal dispersion was observed, in fact, $\mathrm{HCl}$ treated $\mathrm{AC}$ proved to have the lowest dispersion from prepared Co/AC-catalysts. According to CO-chemisorption results addition of promoter metals did not give any particularly high metal dispersion and Ru- and Re-promoted catalysts were measured to have a metal dispersions of $3.2 \%$ (AC-CoRu-IW) and $5.8 \%$ (AC-CoRe-IW) respectively.

Metal contents of the catalysts were measured by ICP analysis. The expected concentration of cobalt added was $10 \mathrm{wt} . \%$ and concentration of ruthenium and rhenium were $0.2 \mathrm{wt} . \%$. The measured concentrations of metals are presented in Table 5. Cobalt concentrations in catalysts were at the expected level around $10 \mathrm{wt}$. \% except in catalyst AC-Co-IW which contained only $5.9 \mathrm{wt}$. \% of cobalt. The reason for this might be the preparation step and miscalculation the amount of cobalt. The concentration of promoter metals was expected to be $0.2 \mathrm{wt}$. \%. The concentration of promoter Ru was in desired concentration, $0.24 \mathrm{wt}$. \%. Measured value of Re was $0.39 \mathrm{wt} . \%$. This double sized value must have caused the preparation step in which the addition of a very small amount of liquid promoter was difficult. Other metals including calcium, iron, potassium, sodium and magnesium were also measured to verify if some traces of metal were left from the preparation process of AC. Acid treated catalysts $\mathrm{AC}-\mathrm{HCl}-\mathrm{Co}-\mathrm{IW}$ and $\mathrm{AC}-\mathrm{HNO}_{3}-\mathrm{Co}-\mathrm{IW}$ contained these metals less than $0.02 \%$. The concentration of metal Ca was $0.02 \mathrm{wt}$. \% and concentration of metals $\mathrm{Fe}, \mathrm{Na}, \mathrm{K}$ and Mg were 0.01 wt. \% or less and could be expected that no interference from these metals should be present in catalytic use. Other catalysts (AC-Co-IW, AC-CoRu-IW, AC-CoRe-IW, and AC-Co-US) contained Ca $<0.04$ wt. $\%, \mathrm{Fe}<0.06$ wt. $\%$ and $\mathrm{Mg}<0.03$ wt. \% and these values were quite low. Instead, concentrations of $\mathrm{Na}$ and $\mathrm{K}$ were higher; $\mathrm{Na}<0.35 \mathrm{wt} . \%$ and $\mathrm{K}<0.11$ wt. \%. These metals might be traces from pulping process and might interfere the catalytic activity in a negative way. [30, 31]

SEM and TEM analyses were used to verify catalyst morphology. From FESEM and TEM images (Figure 2) taken from the catalyst AC-Co-IW can be observed that Co-particles size were around 10-20 nm which was 
quite close to results from CO-chemisorption in which average Co particle size was determined to be 11.6 $\mathrm{nm}$ (Table 4). TEM images of AC-Co-IW also highlighted that the active metal was present in the form of spherical particles with dimensions of about $10-20 \mathrm{~nm}$ quite well distributed on the support surface.

SEM-EDS analyses were performed for calcined Co/AC-catalysts. The point analyze were performed at different locations and marked in the SEM images. All elements were auto-detected using Oxford Instruments INCA software. Figure 3 showed the SEM-EDS analyze sites for catalyst AC-HNO $3-\mathrm{Co}-\mathrm{IW}$. From SEM-EDS analyses, only major components ( $C, O$ and $C o$ ) are shown in Table 6. The SEM-EDS analyses also indicated the addition of Co on the catalyst surface.

XRD measurements were performed for calcined but not reduced Co/AC-catalysts. XRD was used to confirm the presence of cobalt in the catalysts and also to verify metal particle size. From XRD diffraction patterns, it was observed that catalysts showed very broad peaks for Co oxides, indicating a high cobalt metal dispersion and/or amorphous phase of support [32,33]. Since the broad peaks detected from XRD patterns calculation of cobalt metal particle size, based on Scherrer equation was not reliable. However from the XRD diffraction pattern (Figure 4) broad peaks indicated to $\mathrm{CoO}(111)$ at 2 theta $=36.7^{\circ}$ and $\mathrm{CoO}(200)$ at 2 theta $=42.6^{\circ}$, according to standard JCPDS file number (CoO 04-005-4912) which proved the presence of cobalt in catalysts.

\subsection{Reducibility of catalysts}

\subsubsection{Temperature programmed reduction (TPR)}

According to the literature [34] from the $\mathrm{H}_{2}$-TRP profile of Co/AC-catalysts three major peaks could be found; the first peak at around $320^{\circ} \mathrm{C}$ corresponding the reduction of $\mathrm{CO}_{3} \mathrm{O}_{4}$ to $\mathrm{CoO}$ and second high-temperature peak at $450{ }^{\circ} \mathrm{C}$ related to the reduction of $\mathrm{CoO}$ to metallic cobalt, the third broad peak maximum around 600

${ }^{\circ} \mathrm{C}$ is attributed to methane formation which is originated from the reduction of surface functional groups on the $\mathrm{AC}$ surface by $\mathrm{H}_{2}$. From the $\mathrm{H}_{2}$-TRP profile (Figure 5) in some cases, a small peak at $100{ }^{\circ} \mathrm{C}$ was detected which is due to desorption of residue moisture adsorbed on the catalysts surface. Also, the weak reduction 
peak at around $220{ }^{\circ} \mathrm{C}$ could be found and is due to decomposition of residual cobalt nitrate. The first reduction peak for all catalysts is found at temperature $320-380{ }^{\circ} \mathrm{C}$ and the intensity is about the same for all. With second peak reduction step corresponding to the reduction of $\mathrm{CoO}$ and cobalt oxides to $\mathrm{Co}^{\circ}$ there is more variety with reduction temperatures from 370 to $490{ }^{\circ} \mathrm{C}$. A summary of $\mathrm{H}_{2}$-TPR reduction temperature shifts is presented in Table 7. The treatment with $\mathrm{HNO}_{3}\left(\mathrm{AC}-\mathrm{HNO}_{3}-\mathrm{Co}-\mathrm{IW}\right)$ seemed to shift the second reduction step to a lower temperature at $370{ }^{\circ} \mathrm{C}$

The influence of support material and interaction between support and metal oxide can be observed when AC supported catalysts was compared to the conventional $\mathrm{SiO}_{2}$ supported catalyst synthesized and characterized in a previous work [35]. Carbon supported catalysts presented little higher reduction temperatures referred to the first reduction step with respect with traditional FT catalysts $[36,37]$. The first peak of reduction $\mathrm{Co}_{3} \mathrm{O}_{4}$ to $\mathrm{CoO}$ was around $260{ }^{\circ} \mathrm{C}$ for silica supported $\left(\mathrm{SiO}_{2}-\mathrm{Co}\right)$ and $320-380{ }^{\circ} \mathrm{C}$ for $\mathrm{AC}$ supported Co-catalysts while second peak related to the reduction of $\mathrm{CoO}$ to metallic cobalt showed remarkable lower temperature for $\mathrm{AC}$ supported catalysts compared to silica supported catalyst $\left(\mathrm{SiO}_{2}-\mathrm{Co}\right)$, in fact, the average temperature of carbon supported catalyst is around $\mathrm{T}=420{ }^{\circ} \mathrm{C}$, while the reduction temperature for the transition from $\mathrm{CoO}$ to $\mathrm{Co}$ presented by the $\mathrm{SiO}_{2}$ supported catalysts is equal to $\mathrm{T}=780$ ${ }^{\circ} \mathrm{C}$ due to the presence of Co-silicates species, which are hard reducible species [38].

\subsubsection{Temperature programmed oxidation (TPO)}

The degree of reduction (Table 8) was calculated from the theoretical value of moles of oxygen per consumed moles of oxygen using the measured Co metal content value from the ICP analysis (see Table 5). The addition of Re seemed to affect the reduction degree of the catalyst AC-CoRe-IW with the highest degree of reduction $72 \%$. Catalyst $\mathrm{AC}-\mathrm{HNO}_{3}$-Co-IW oxidized with $\mathrm{HNO}_{3}$ had a degree of reduction $66 \%$. With catalyst AC-CoReIW, the degree of reduction was higher when compared to conventional CoRe-catalyst supported on $\mathrm{Al}_{2} \mathrm{O}_{3}$ from literature [39]. The lowest degree of reduction was calculated on catalysts AC-Co-US and it was equal to $25 \%$. Low values of reduction were measured also with catalysts AC-CoRu-IW (38 \%) and AC-Co-IW (39 
\%). One of the reasons for the low degree of reduction might be explained due to rather small cobalt particle sizes, which are harder to reduce. Overall, these values were well comparable with other tested Co/ACcatalysts from the literature [40].

\subsection{Surface functional groups}

Functional groups of activated carbon surface were determined by diffuse reflectance Fourier transformed IR (DRIFT) analysis and it was possible to identify some of the oxygen-containing functionality. One of the problems using infrared spectroscopy (FTIR) of carbonaceous materials is that they are effective black body absorbers and are too opaque for direct transmission analysis on the mid-infrared spectral region. The addition of $\mathrm{KBr}$ intensifies the signal but the signal is still too weak to obtain. An alternative technique is to use (DRIFT) [41, 42]. Although IR spectroscopy does not provide quantitative information about carbon surface chemistry, it can identify groups created or destroyed. Produced AC's were compared with commercial AC. Main peaks at area $3400 \mathrm{~cm}^{-1}, 1620 \mathrm{~cm}^{-1}$ and $1620 \mathrm{~cm}^{-1}$ can be found from all AC's. From the spectrum (Figure 6), few changes with different AC's peaks can be detected at the area $1000-2000 \mathrm{~cm}^{-1}$. Notable changes with peaks from $\mathrm{AC}$ treated with $\mathrm{HNO}_{3}$ were at area $1760 \mathrm{~cm}^{-1}$ (carbonyl stretching of quinones and carboxylic acids), $1590 \mathrm{~cm}^{-1}\left(\mathrm{C}=\mathrm{C}\right.$ stretching in the form of aromatic rings) and $1240 \mathrm{~cm}^{-1}(\mathrm{C}-\mathrm{O}$ stretches presumably from both carboxylic acid groups and phenolic hydroxyls) [43, 44]. Peaks at $1570 \mathrm{~cm}^{-1}$, $1380 \mathrm{~cm}^{-1}$ and $1240 \mathrm{~cm}^{-1}$ might also indicate to $\mathrm{C}=\mathrm{N}$ structure[23].

XPS measurements were performed for calcined but not reduced Co/AC-catalysts to get more specific information from functional groups on activated carbon, especially carbon-oxygen, and cobalt complexes.

Figure 7a shows the high resolution C1s-spectra and reveals components corresponding carbidic carbon (BE= 282.6-282.9 eV); graphitic or aliphatic carbon ( $B E=284.6-285.1 \mathrm{eV}$ ); carbon species in alcohol or ether groups $(B E=286.3-287.0 \mathrm{eV})$; carbon in carbonyl groups $(B E=287.5-288.1 \mathrm{eV})$; carbon in carboxyl or ester groups $(B E=289.3-290.0 \mathrm{eV})$; and shake-up satellite due $\pi-\pi^{*}$ transition in aromatic rings ( $\left.B E=291.2-292.1 \mathrm{eV}\right)$. Peaks 
in the region $286.3-287.5 \mathrm{eV}$ may also present of structures C-N [45, 46]. From Table 9 can be seen that most of the carbon atoms present in the catalyst are graphitic/aliphatic and about $15-20 \%$ is in carbon-oxygen (or C-N) compounds.

XPS spectrum of O1s-scans is presented in Figure 7b. and represents the oxygen groups on the surface of the catalyst. In the 01s-spectra functional oxygen groups are divided in three different peaks representing double bonded oxygen $(C=O)$ to carbon in carbonyl, carboxyl, oxygen of quinone groups ( $B E=530.4-530.8 \mathrm{eV})$; single bonded oxygen $(C-O)$ in alcohol or ester groups $(B E=532.4-533.1 \mathrm{eV})$ and chemisorbed oxygen or water $(B E=$ 534.8-535.6 eV). Results showed that oxygen is in the form of double bonded oxygen and single bonded oxygen quite evenly (Table 9). Moreover, catalyst AC-Co-US contained more of double bonded oxygen (carbonyl/carboxyl) compounds than other catalysts while catalyst $\mathrm{AC}-\mathrm{HNO}_{3}-\mathrm{Co}-\mathrm{IW}$ contained the least oxygen-containing groups from the catalysts.

XPS results of N1s-scans are presented in Table 9. The intensities of peaks from N1s spectrum was low but showed that catalysts $\mathrm{AC}-\mathrm{Co}-\mathrm{PR}$ and $\mathrm{AC}-\mathrm{HNO}_{3}-\mathrm{Co}-\mathrm{IW}$ contained more nitrogen than other catalysts.

The Co2p-scan XPS results of the catalysts (Figure 7c) highlighted that, as already confirmed by the TPR, Co is present in its oxidized forms $\mathrm{Co}_{3} \mathrm{O}_{4}, \mathrm{CO}_{2} \mathrm{O}_{3}$ and $\mathrm{CoO}(\mathrm{BE}=779-782 \mathrm{eV})$ and no $\mathrm{Co}^{\circ}(\mathrm{BE}=778 \mathrm{eV})$ has been found in any of the catalysts [47]. The lack of metallic Co is attributable to the fact that the Co-precursor used has an oxidation state equal to +3 and no further reduction treatments have been applied before XPS analysis.

Figure 8 highlights that the treatment with ultrasound causes a huge decrease in the content of graphitic or aliphatic carbon in AC-Co-US catalyst. It is wide discussed that ultrasounds are capable of degrading carbonyls and moreover a suitable technique to degrade graphite into other compounds [48, 49].

\section{Conclusions}

A series of Co-based catalysts supported on activated carbon and eventually promoted with Ru or Re have been synthesized and characterized. Different pretreatments and metal addition procedures seemed to have a high impact to the prepared Co-catalyst. 
Prepared carbon support seemed to have many attractive properties including high specific surface area, proper pore distribution and high volume of mesopores and rather low ash value, which could be decreased even to zero by acid treatment. Acid treatment seemed to be important for removing inorganic compounds e.g. metals from the carbon support, which might affect to catalytic activity. Analyses including ICP-OES, SEM, TEM and XRD indicated that cobalt was successfully added onto carbon support in all catalyst preparation cases.

Some of the prepared Co-catalysts seemed to have good qualities (for FT-catalyst). Rather high dispersion (10.1\%) of the active metal (cobalt) was measured with Co-catalyst prepared by ultrasonic assisted impregnation method. Otherwise, there was an indication that a small metal particle size was difficult to reduce (TPO). TPR results highlighted that carbon supported cobalt catalysts proved to have lower reduction temperatures referred to the second reduction step of cobalt oxide to metallic cobalt if compared with $\mathrm{SiO}_{2}$ supported FT catalyst. Moreover, pretreatment with $\mathrm{HNO}_{3}$ seemed to have a positive effect on reduction temperatures and to a degree of reduction compared to other prepared Co/AC-catalysts. Also, the addition of the promoter Re did seem to improve the reduction degree of cobalt as measured in the TPO measurements. According to XPS analyses, different preparation techniques seemed to have an impact on the catalyst surface structure. Further, these prepared cobalt catalysts needs a thorough testing in the pilot scale FT plant.

\section{Acknowledgements}

The authors acknowledge the EU/European Regional Development Fund, Leverage from the EU program (within project nr. A71029) for financial support.

\section{References}


402 [1] Demirbaş A, Arslan G, Pehlivan E (2006) Energy Sources, Part A: Recovery, Utilization, and

403 Environmental Effects 28:627-638

404 [2] Lam E, Luong JHT (2014) ACS Catalysis 4:3393-3410

405 [3] Rodríguez-Reinoso F (1998) Carbon 36:159-175.

406 [4] Bezemer GL, Radstake PB, Falke U, Oosterbeek H, Kuipers HPCE, van Dillen AJ, et al. (2006) Journal of 407 Catalysis 237:152-161.

408 [5] Khodakov AY (2009) Catalysis Today 144:251-257

409

[6] Jean-Marie A, Griboval-Constant A, Khodakov AY, Diehl F (2009) Comptes Rendus Chimie 12:660-667

410

[7] Tsakoumis NE, Rønning M, Borg $\varnothing$, Rytter E, Holmen A (2010) Catalysis Today 154:162-182

411

[8] Iglesia E (1997) Applied Catalysis A: General 161:59-78

412

[9] Gnanamani MK, Jacobs G, Shafer WD, Davis BH (2013) Catalysis Today 215:13-17

413

[10] van Steen E, Prinsloo FF (2002) Catalysis Today 71:327-334

414

[11] Zaman M, Khodadi A, Mortazavi Y (2009) Fuel Processing Technology 90:1214-1219

415

416

417

418

[12] Serp P, Machado B (2015) Carbon (Nano) Materials for Catalysis, Nanostructured Carbon Materials for Catalysis, the Royal Society of Chemistry, pp. 1-45

[13] Fu T, Li Z (2015) Chemical Engineering Science 135:3-20

[14] Bitter JH, de Jong KP (2008) Preparation of Carbon-Supported Metal Catalysts, In: Serp P, Figueiredo JL (Eds) Carbon Materials for Catalysis. John Wiley \& Sons, Inc., pp. 157-176

[15] Moreno-Castilla C, Ferro-Garcia MA, Joly J P, Bautista-Toledo I, Carrasco-Marin F, Rivera-Utrilla J (1995) Langmuir 11:4386-4392

[16] Kang J, Zhang S, Zhang Q, Wang Y (2009) TOC 121:2603-2606

[17] Kogelbauer A, Goodwin JG, Oukaci R (1996) Journal of Catalysis 160:125-133

[18] Eschemann TO, Oenema J, de Jong KP (2016) Catalysis Today 261:60-66

[19] Jacobs G, Das TK, Zhang Y, Li J, Racoillet G, Davis BH (2002) Applied Catalysis A: General 233:263-281

[20] Shu S, Guo J, Liu X, Wang X, Yin H, Luo D (2016) Applied Surface Science, Part B 360:684-692

[21] Zabihi M, Khorasheh F, Shayegan J (2015) Reaction Kinetics, Mechanisms and Catalysis 114:611-628

[22] Munnik P, de Jongh PE, de Jong KP (2015) Chemical Reviews 115:6687-6718

[23] Serp P, Joseph JL (2009) Carbon Materials for Catalysis, Wiley, Canada 
[24] Khodakov AY, Chu W, Fongarland P (2007) Chemical Reviews 107:1692-1744

[25] Zowtiak JM, Bartholomew CH (1983) Journal of Catalysis 83:107-120

[26] Reuel RC, Bartholomew CH (1984) Journal of Catalysis 85:63-77

[27] Kababji AH, Joseph B, Wolan JT (2009) Catalysis Letters 130:72-78

[28] Maitlis MP, de Klerk A (2013) Greener Fischer-Tropsch Processes for Fuels and Feedstocks, Wiley-VCH

[29] Romar H, Lillebo AH, Tynjala P, Hu T, Holmen A, Blekkan EA, Lassi U (2016) Journal of Materials Science Research 5:39-49

[30] Tsakoumis NE, Rønning M, Borg $\varnothing$, Rytter E, Holmen (2010) A Catalysis Today 154:162-182

[31] Lilleb $\varnothing$ AH, Patanou E, Yang J, Blekkan EA, Holmen A (2013) Catalysis Today 215:60-66

[32] Song X, et al. (2013) Applied Catalysis A: General Volume 452:155-162

[33] Beswick O, et al. (2017) Catalysis Today 279, Part 1:29-35

[34] Wang T, Dinga Y, Xionga J, Yana L, Zhua H, Lua Y (2006) Catalysis Letters 107:47-52

[35] Comazzi A, Pirola C, Di Michele A, Compagnoni M, Galli F, Rossetti I, et al. (2016) Applied Catalysis A: General 520:92-98

[36] Lin H, Chen Y (2004) Materials Chemistry and Physics 85:171-175

[37] Olusola OJ, Sudip M (2016) Journal of Petroleum Technology and Alternative Fuels 7:1-12

[38] Ming H, Baker BG (1995) Applied Catalysis A: General 123:23-36

[39] Borg $\varnothing$, et al. (2007) Journal of Catalysis 248:89-100

[40] Zhang, Y, et al. (2007) Fischer-Tropsch synthesis, Catalysts and Catalysis, Edit, Davis BH and Occelli ML, p.87-99

[41] Jagiello J (1994) Langmuir 10:2778-2785

[42] Moreno-Castilla C, López-Ramón MV, Carrasco-Marín F (2000) Carbon 38:1995-2001

[43] Dandekar A, Baker R, Vannice M (1998) Carbon 36:1821-1831

[44] Mangun CL, Benak KR, Daley MA, Economy J (1999) Chemistry of Materials 11: 3476-3483

[45] Biniak S, Szymański G, Siedlewski J, Świtkowski A (1997) Carbon 35:1799-1810

[46] Nahil MA, Williams PT (2012) Waste Biomass Valor 3:117-130

[47] Biesinger MC, et.al (2011) Applied Surface Science 257:2717-2730 
457

458

459

460

461

462

463

464

465

466

467

468

469

470

471

472

473

474

475

476
[48] Suslick KS, Hyeon T, Fang M, Cichowlas AA (1995) Materials Science and Engineering: A 204:186-192

[49] Guittoneau F, Abdelouas A, Grambow B, Huclier S (2010) Ultrasonics Sonochemistry 17:391-398 
478

479 Table 1. A summary of catalyst denotation: precursor salts, impregnation methods and calcination.

480

481

482

483

484

485

486

487

488

489

490

491

492

493

494

495

496

497

498

499

500

501 


\begin{tabular}{|c|c|c|c|c|}
\hline Catalyst & Metal content & Metal salts used & $\begin{array}{l}\text { Impregnation method } \\
\text { used }\end{array}$ & Calcination \\
\hline AC-Co-IW & 10 wt. $\%$ Co & $\mathrm{Co}\left(\mathrm{NO}_{3}\right)_{2} \cdot 6 \mathrm{H}_{2} \mathrm{O}$ & incipient wetness & $320^{\circ} \mathrm{C}, 16 \mathrm{~h}, \mathrm{~N}_{2}$-flow \\
\hline AC-HCl-Co-IW* & 10 wt. $\%$ Co & $\mathrm{Co}\left(\mathrm{NO}_{3}\right)_{2} \cdot 6 \mathrm{H}_{2} \mathrm{O}$ & incipient wetness & $320^{\circ} \mathrm{C}, 16 \mathrm{~h}, \mathrm{~N}_{2}$-flow \\
\hline $\mathrm{AC}-\mathrm{HNO}_{3}-\mathrm{Co}-\mathrm{IW} \mathrm{W}^{* *}$ & 10 wt. $\%$ Co & $\mathrm{Co}\left(\mathrm{NO}_{3}\right)_{2} \cdot 6 \mathrm{H}_{2} \mathrm{O}$ & incipient wetness & $320^{\circ} \mathrm{C}, 16 \mathrm{~h}, \mathrm{~N}_{2}$-flow \\
\hline AC-CoRu-IW & $\begin{array}{l}10 \text { wt. } \% \text { Co } \\
0.2 \text { wt. } \% \text { Ru }\end{array}$ & $\begin{array}{l}\mathrm{Co}\left(\mathrm{NO}_{3}\right)_{2} \cdot 6 \mathrm{H}_{2} \mathrm{O} \\
\mathrm{Ru}(\mathrm{NO})\left(\mathrm{NO}_{3}\right)_{3}\end{array}$ & $\begin{array}{l}\text { one-step incipient } \\
\text { wetness }\end{array}$ & $320^{\circ} \mathrm{C}, 16 \mathrm{~h}, \mathrm{~N}_{2}$-flow \\
\hline AC-CoRe-IW & $\begin{array}{l}\text { 10wt. \% Co } \\
0.2 \text { wt. \% Re }\end{array}$ & $\begin{array}{l}\mathrm{Co}\left(\mathrm{NO}_{3}\right)_{2} \cdot 6 \mathrm{H}_{2} \mathrm{O} \\
\mathrm{ReO}_{4} \mathrm{H}\end{array}$ & $\begin{array}{l}\text { one-step incipient } \\
\text { wetness }\end{array}$ & $320^{\circ} \mathrm{C}, 16 \mathrm{~h}, \mathrm{~N}_{2}$-flow \\
\hline AC-Co-PR & 10 wt. $\%$ Co & $\mathrm{Co}\left(\mathrm{NO}_{3}\right)_{2} \cdot 6 \mathrm{H}_{2} \mathrm{O}$ & precipitation with urea & $320^{\circ} \mathrm{C}, 16 \mathrm{~h}, \mathrm{~N}_{2}$-flow \\
\hline AC-Co-US & 10 wt. \% Co & $\mathrm{Co}\left(\mathrm{NO}_{3}\right)_{2} \cdot 6 \mathrm{H}_{2} \mathrm{O}$ & $\begin{array}{l}\text { ultrasonic assisted } \\
\text { incipient wetness }\end{array}$ & $320^{\circ} \mathrm{C}, 16 \mathrm{~h}, \mathrm{~N}_{2}$-flow \\
\hline
\end{tabular}

504

505

506

507

508

509

510

511

512

513

514

515

516

517

*) AC demineralized with $\mathrm{HCl}$ and ${ }^{* *}$ ) $\mathrm{AC}$ oxidized with $\mathrm{HNO}_{3}$ before impregnation. 
519 Table 2. Surface area, pore volume, pore size, pore distribution, total carbon content and ash content of 520 the raw lignin, activated carbon and acid treated activated carbons.

521

522

523

524

525

526

527

528

529

530

531

532

533

534

535

536

537

538 
540

\begin{tabular}{|c|c|c|c|c|c|c|c|c|}
\hline \multirow[t]{2}{*}{ Sample } & \multirow{2}{*}{$\begin{array}{c}\text { BET } \\
\text { Surface } \\
\text { area } \\
\left(\mathrm{m}^{2} / \mathrm{g}\right)\end{array}$} & \multirow[b]{2}{*}{$\begin{array}{c}\text { Pore } \\
\text { volume } \\
\left(\mathrm{cm}^{3} / \mathrm{g}\right)\end{array}$} & \multirow[b]{2}{*}{$\begin{array}{l}\text { Pore } \\
\text { size } \\
(\mathrm{nm})\end{array}$} & \multicolumn{3}{|c|}{ BJH pore distribution } & \multirow[b]{2}{*}{$\begin{array}{c}\text { Carbon } \\
\text { content } \\
(\%)\end{array}$} & \multirow[b]{2}{*}{$\begin{array}{l}\text { Ash } \\
\text { (\%) }\end{array}$} \\
\hline & & & & $\begin{array}{c}\text { Micro- } \\
\text { pores } \\
(\%)\end{array}$ & $\begin{array}{c}\text { Meso- } \\
\text { pores } \\
(\%)\end{array}$ & $\begin{array}{c}\text { Macro- } \\
\text { pores } \\
(\%)\end{array}$ & & \\
\hline Lignin, untreated & 4.6 & 0.02 & 18 & n.d. & n.d. & n.d. & 65 & n.d. \\
\hline$A C$ & 810 & 0.41 & 2 & 32 & 62 & 6 & 96 & 6.1 \\
\hline $\begin{array}{l}\text { AC, treated with } \\
\mathrm{HCl}\end{array}$ & 822 & 0.41 & 2 & 34 & 60 & 6 & 95 & 4.8 \\
\hline $\begin{array}{l}\text { AC, treated with } \\
\mathrm{HNO}_{3}\end{array}$ & 714 & 0.35 & 2 & 33 & 61 & 6 & 85 & 0.0 \\
\hline
\end{tabular}

542

543

544

545

546

547

548

549

550

551

552

553 
555

556 Table 3. Elemental analysis $(\mathrm{C}, \mathrm{H}, \mathrm{O}, \mathrm{N})$ for activated carbon supports.

557

558

559

560

561

562

563

564

565

566

567

568

569

570

571

572

573 
574 Lahti et al. Tab 3.

575

\begin{tabular}{llcccc}
\hline Sample & Treatment & $\begin{array}{c}\mathrm{C} \\
(\%)\end{array}$ & $\begin{array}{c}\mathrm{H} \\
(\%)\end{array}$ & $\begin{array}{c}\mathrm{O} \\
(\%)\end{array}$ & $\begin{array}{c}\mathrm{N} \\
(\%)\end{array}$ \\
\hline $\mathrm{AC}$ & Untreated & 86.4 & 0.7 & 2.2 & 0.6 \\
$\mathrm{AC}$ & $30 \% \mathrm{HNO}_{3}$, reflux 3h & 59.6 & 1.9 & 0 & 1.4 \\
$\mathrm{AC}$ & $30 \% \mathrm{HCl}$, reflux 3h & 79.8 & 1.2 & 4.3 & 0.5 \\
\hline
\end{tabular}

576

577

578

579

580

581

582

583

584

585

586

587

588

589 
591

592 Table 4. Surface area, pore volume, pore size, cobalt metal dispersion, metal particle size and metal surface 593 area of Co/AC-catalysts.

594

595

596

597

598

599

600

601

602

603

604

605

606

607

608

609

610 
611 Lahti et al. Tab 4.

612

613

\begin{tabular}{lccccccc}
\hline Catalyst* & $\begin{array}{c}\text { BET } \\
\text { Surface } \\
\text { area } \\
\left(\mathrm{m}^{2} / \mathrm{g}\right)\end{array}$ & $\begin{array}{c}\text { Pore } \\
\text { volume } \\
\left(\mathrm{cm}^{3} / \mathrm{g}\right)\end{array}$ & $\begin{array}{c}\text { Average } \\
\text { pore size } \\
(\mathrm{nm})\end{array}$ & $\begin{array}{c}\text { Co metal } \\
\text { dispersion } \\
(\%)\end{array}$ & $\begin{array}{c}\text { Co metal } \\
\text { particle size } \\
(\mathrm{nm})\end{array}$ & $\begin{array}{c}\text { Co metal } \\
\text { surface } \\
\text { area } \\
\left(\mathrm{m}^{2} / \mathrm{g}\right.\end{array}$ & $\begin{array}{c}\text { Co metal } \\
\text { surface } \\
\text { area } \\
\left(\mathrm{m}^{2} / \mathrm{g} \text { of }\right. \\
\text { metal })\end{array}$ \\
\hline AC-Co-IW & 710 & 0.35 & 2 & 8.6 & 11.6 & 5.8 & 58.1 \\
AC-HCl-Co-IW & 610 & 0.30 & 2 & 0.7 & 138.5 & 0.5 & 4.9 \\
AC-HNO3-Co-IW & 640 & 0.32 & 2 & 3.4 & 29.8 & 2.3 & 22.7 \\
AC-CoRu-IW & 640 & 0.29 & 2 & 3.2 & 31.0 & 2.2 & 21.8 \\
AC-CoRe-IW & 630 & 0.31 & 2 & 5.8 & 17.2 & 3.9 & 39.2 \\
AC-Co-PR & 680 & 0.34 & 2 & n.d. & n.d. & n.d. & n.d. \\
AC-Co-US & 600 & 0.28 & 2 & 10.1 & 9.8 & 6.9 & 68.6
\end{tabular}

$614 *$ ) Preparation methods presented in Table 1.

615 n.d. $=$ not determined

616

617

618

619

620

621

622

623

624

625

626 
627 Lahti et al. Table captions

628

629 Table 5. Metal content in catalysts from ICP analysis.

630

631

632

633

634

635

636

637

638

639

640

641

642

643

644

645

646

647

648

649

650

651

652

653 
655 Lahti et al. Table 5.

657

\begin{tabular}{lcccccccc}
\hline Catalyst & $\begin{array}{c}\mathrm{Co} \\
\text { wt.\% }\end{array}$ & $\begin{array}{c}\mathrm{Ru} \\
\text { wt.\% }\end{array}$ & $\begin{array}{c}\mathrm{Re} \\
\text { wt.\% }\end{array}$ & $\begin{array}{c}\mathrm{Ca} \\
\text { wt.\% }\end{array}$ & $\begin{array}{c}\mathrm{Fe} \\
\text { wt. } \%\end{array}$ & $\begin{array}{c}\mathrm{Na} \\
\text { wt.\% }\end{array}$ & $\begin{array}{c}\mathrm{K} \\
\text { wt.\% }\end{array}$ & $\begin{array}{c}\mathrm{Mg} \\
\text { wt.\% }\end{array}$ \\
\hline AC-Co-IW & 5.9 & & & 0.02 & 0.02 & 0.30 & 0.11 & $<0.01$ \\
AC-HCl-Co-IW & 11.1 & & & 0.02 & 0.01 & 0.01 & $<0.01$ & $<0.01$ \\
AC-HNO3-Co-IW & 8.3 & & & 0.02 & 0.01 & 0.01 & $<0.01$ & $<0.01$ \\
AC-CoRe-IW & 9.1 & & 0.39 & 0.03 & 0.03 & 0.35 & 0.10 & 0.02 \\
AC-CoRu-IW & 9.3 & 0.24 & & 0.04 & 0.06 & 0.13 & 0.07 & 0.03 \\
AC-Co-PR & 9.2 & & & 0.01 & 0.02 & 0.25 & 0.09 & $<0.01$ \\
AC-Co-US & 9.8 & & & 0.04 & 0.06 & 0.21 & 0.07 & 0.03 \\
\hline
\end{tabular}

658

659

660

661

662

663

664

665

666

667

668

669

670

671 
672 Lahti et al. Table captions

673

674 Table 6. SEM-EDS spectrum labels from catalyst $\mathrm{AC}^{-} \mathrm{HNO}_{3}$-Co-IW.

675

676

677

678

679

680

681

682

683

684

685

686

687

688

689

690

691 
692 Lahti et al. Tab 6.

693

\begin{tabular}{lcccccccccc}
\hline $\begin{array}{l}\text { Spectrum } \\
\text { Label }\end{array}$ & S147 & S148 & S149 & S150 & S151 & S152 & S153 & S154 & S155 & S156 \\
\hline C & 26.22 & 20.98 & 35.43 & 20.39 & 27.05 & 63.41 & 22.03 & 24.76 & 35.54 & 22.52 \\
O & 1.06 & 20.11 & 2.40 & 0.71 & 1.40 & 8.44 & 0.85 & 0.99 & 15.91 & 0.84 \\
Co & 71.82 & 58.53 & 60.49 & 75.82 & 70.36 & 27.39 & 76.10 & 72.67 & 48.19 & 75.32
\end{tabular}

694

695

696

697

698

699

700

701

702

703

704

705

706

707

708 
710

711 Table 7 . Temperatures $\left({ }^{\circ} \mathrm{C}\right)$ for reduction steps and total $\mathrm{H}_{2}$-consumption.

712

713

714

715

716

717

718

719

720

721

722

723

724

725

726

727

728 
730

\begin{tabular}{lccc}
\hline & \multicolumn{2}{c}{$\begin{array}{c}\text { Phase transformation } \\
\mathrm{T}\left({ }^{\circ} \mathrm{C}\right)\end{array}$} & $\begin{array}{c}\text { Total } \\
\text { Catalyst }\end{array}$ \\
\cline { 2 - 3 } & 330 & $\begin{array}{c}\mathrm{H}_{2} \text {-consumption } \\
\left(\mathrm{mmol} / \mathrm{g}_{\text {cat }}\right)\end{array}$ \\
\hline AC-Co-IW & 350 & 480 & 4.0 \\
AC-HCl-Co-IW & 320 & 410 & 3.3 \\
AC-HNO 3 -Co-IW & 330 & 370 & 6.3 \\
AC-CoRu-IW & 380 & 420 & 7.0 \\
AC-CoRe-IW & 340 & 480 & 5.2 \\
AC-Co-PR & 340 & 470 & 5.0 \\
AC-Co-US & 260 & 490 & 5.7 \\
Co-SiO & & 780 & n.d.
\end{tabular}

731

732

733

734

735

736

737

738

739

740

741 
743

744 Table 8 . The degree of reduction at $350^{\circ} \mathrm{C}$ and volume of $\mathrm{O}_{2}$ adsorbed on the catalyst surface.

745

746

747

748

749

750

751

752

753

754

755

756

757

758

759

760

761 
763

\begin{tabular}{lcc}
\hline Catalyst & $\begin{array}{r}\mathrm{O}_{2} \text {-consumption } \\
\left(\mathrm{ml} / \mathrm{g}_{\text {cat }}\right)\end{array}$ & $\begin{array}{c}\text { Degree of reduction } \\
(\%)\end{array}$ \\
\hline AC-Co-IW & 1.2 & 39 \\
AC-HCl-Co-IW & 2.2 & 37 \\
AC-HNO 3 -Co-IW & 1.9 & 66 \\
AC-CoRu-IW & 1.9 & 38 \\
AC-CoRe-IW & 2.2 & 72 \\
AC-Co-PR & 1.8 & 45 \\
AC-Co-US & 1.3 & 25 \\
\hline
\end{tabular}

764

765

766

767

768

769

770

771

772

773

774

775

776 
778

779 Table 9. Spectral parameters of C1s-, O1s-, Co2p- and N1s-scans of catalysts.

780

781

782

783

784

785

786

787

788

789

790

791

792

793

794

795

796

797

798

799

800 
801 Lahti et al. Tab 9.

802

\begin{tabular}{|c|c|c|c|c|c|c|c|c|}
\hline Scan & $\begin{array}{c}\text { Binding } \\
\text { Energy } \\
(\mathrm{eV})\end{array}$ & $\begin{array}{l}\text { AC- } \\
\text { Co- } \\
\text { IW } \\
(A \%)\end{array}$ & $\begin{array}{c}\mathrm{AC}- \\
\mathrm{HCl}- \\
\mathrm{Co}-\mathrm{IW} \\
(\mathrm{A} \%)\end{array}$ & $\begin{array}{c}\mathrm{AC}- \\
\mathrm{HNO}_{3}- \\
\mathrm{Co}-\mathrm{IW} \\
(\mathrm{A} \%)\end{array}$ & $\begin{array}{c}\text { AC- } \\
\text { CoRu- } \\
\text { IW } \\
(\mathrm{A} \%)\end{array}$ & $\begin{array}{c}\text { AC- } \\
\text { CoRe- } \\
\text { IW } \\
(A \%)\end{array}$ & $\begin{array}{c}\text { AC- } \\
\text { Co- } \\
\text { PR } \\
(\mathrm{A} \%)\end{array}$ & $\begin{array}{l}\text { AC- } \\
\text { Co- } \\
\text { US } \\
\text { (A\%) }\end{array}$ \\
\hline \multicolumn{9}{|l|}{ C1s Scan } \\
\hline carbidic carbon & 282 & & & & 7.0 & & & \\
\hline graphitic or aliphatic carbon & $284-285$ & 47.6 & 47.8 & 50.7 & 36.2 & 28.8 & 46.8 & 19.8 \\
\hline $\begin{array}{l}\text { carbon in ethers, alcohols, } \\
\text { phenols, amines, carbonyls, } \\
\text { quinones, carboxyl or ester } \\
\text { groups }\end{array}$ & $286-291$ & 12.6 & 13.0 & 21.9 & 14.7 & 9.8 & 11.8 & 7.9 \\
\hline$\pi-\pi^{*}$ shake-up peaks & $291-292$ & 12.7 & 12.5 & 9.3 & 14.0 & 7.9 & 11.2 & 10.0 \\
\hline \multicolumn{9}{|l|}{ O1s Scan } \\
\hline $\mathrm{C}=\mathrm{O}$ groups & 530 & 9.1 & 10.6 & 9.5 & 11.3 & 25.3 & 12.0 & 32.8 \\
\hline $\mathrm{C}-\mathrm{OH}, \mathrm{C}-\mathrm{O}-\mathrm{C}$ groups & $532-533$ & 10.0 & 8.4 & 2.9 & 9.0 & 14.7 & 9.1 & 11.0 \\
\hline chemisorbed O or water & $534-536$ & 3.6 & 2.4 & 0.9 & 3.5 & 4.2 & 2.9 & 5.9 \\
\hline Co2p Scan & $779-782$ & 4.0 & 4.8 & 0.9 & 4.6 & 6.0 & 4.8 & 13.8 \\
\hline N1s Scan & 399 & 0.4 & 0.4 & 1.0 & 0.5 & 0.5 & 1.9 & 0.3 \\
\hline
\end{tabular}

803

The peak area is calculated for each sample as atomic percent ratio

804

805

806 
807

808

809

810

811

812

813

814

815

816

817

818

819

820

821

822

823

824

825

826 11

Figure 1. Scheme for the preparation methods of cobalt catalysts on activated carbon support.

Lahti et al. Figure captions

2

813

14 


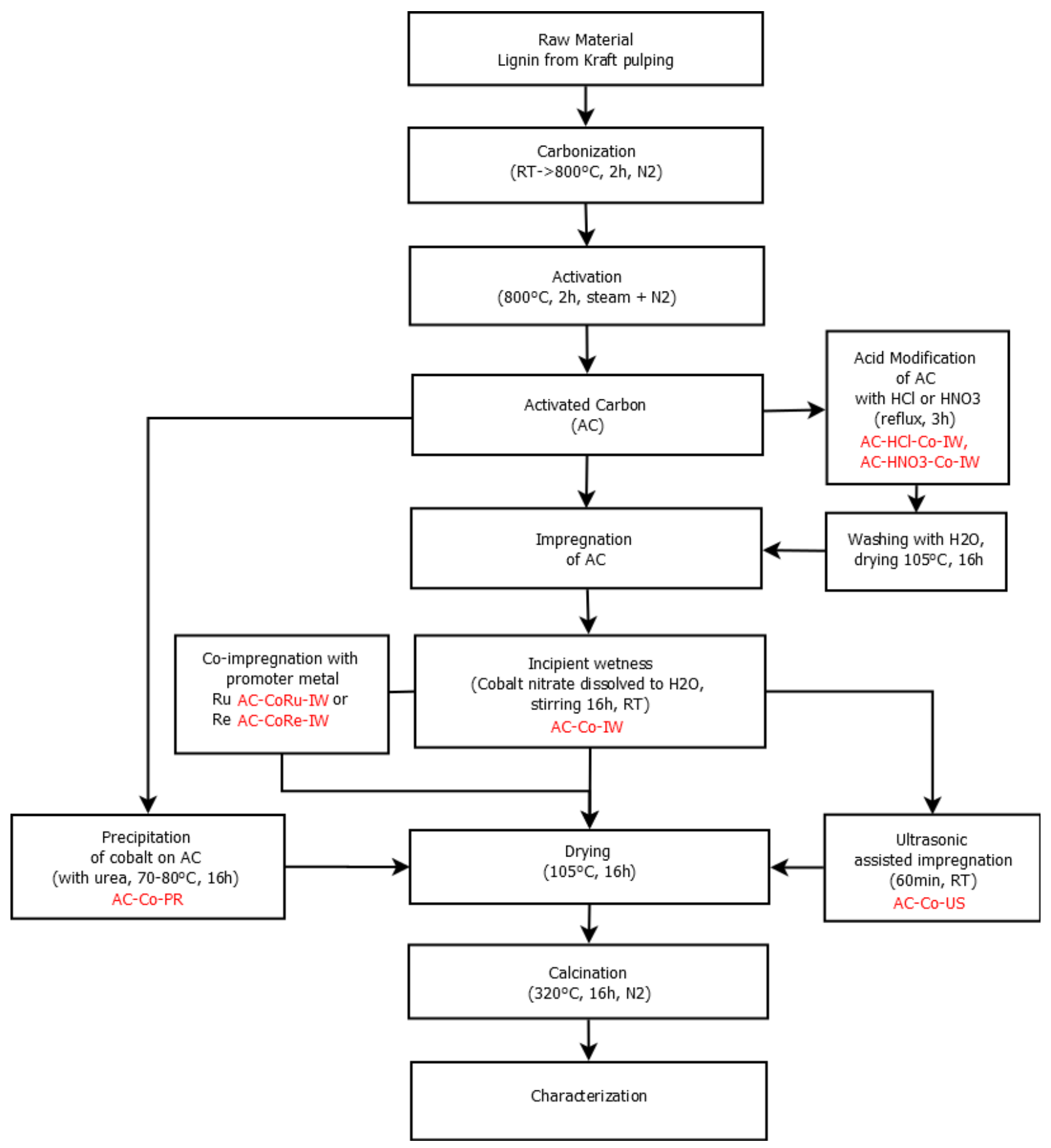


832

833

834

835

836

837

838

839

840

841

842

843

844

845

846

847

848

849

850

851

Figure 2. FESEM (left) and TEM (right) images of catalyst AC-Co-IW. 
852 Lahti et al. Fig 2.

853
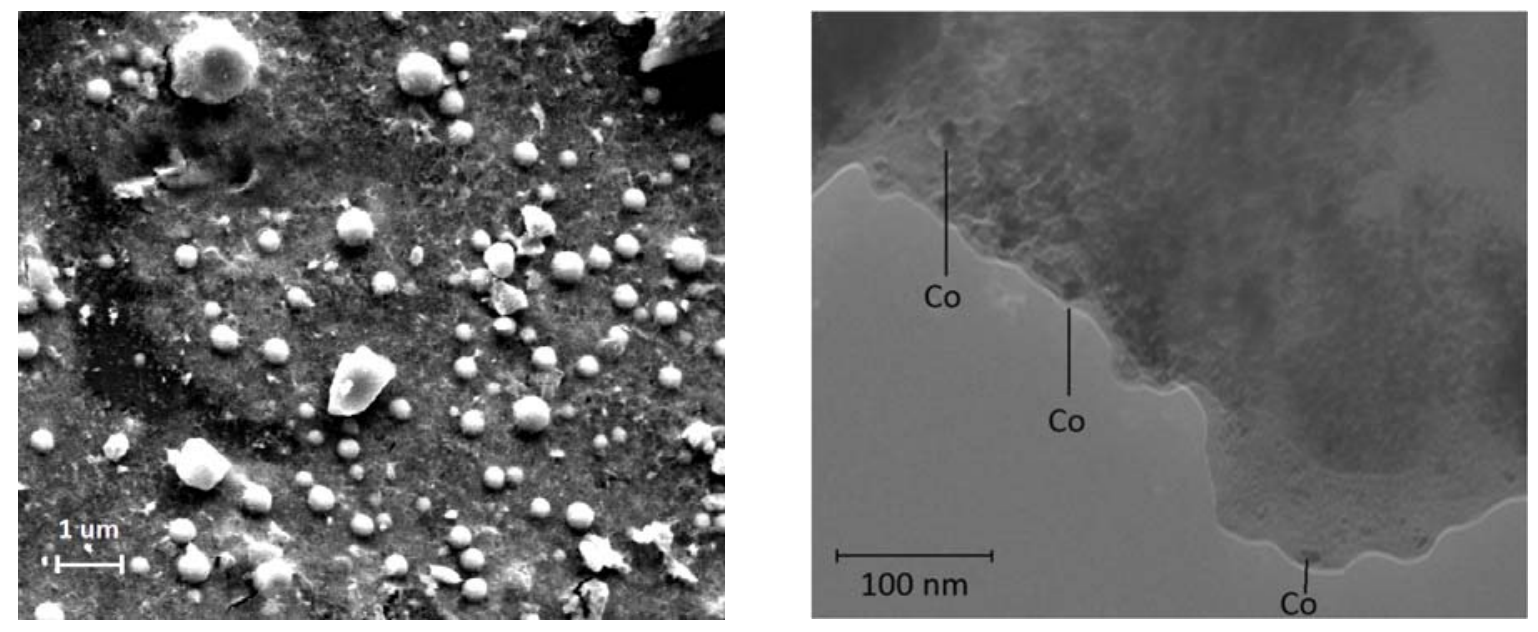

854

855

856

857

858

859

860

861

862

863

864

865 
866

867

868

869

870

871

872

873

874

875

876

877

878

879

880

881

882

883

884

885

Lahti et al. Figure captions

Figure 3. SEM-EDS spectrum from catalyst $\mathrm{AC}-\mathrm{HNO}_{3}-\mathrm{Co}-\mathrm{IW}$.

(1) 


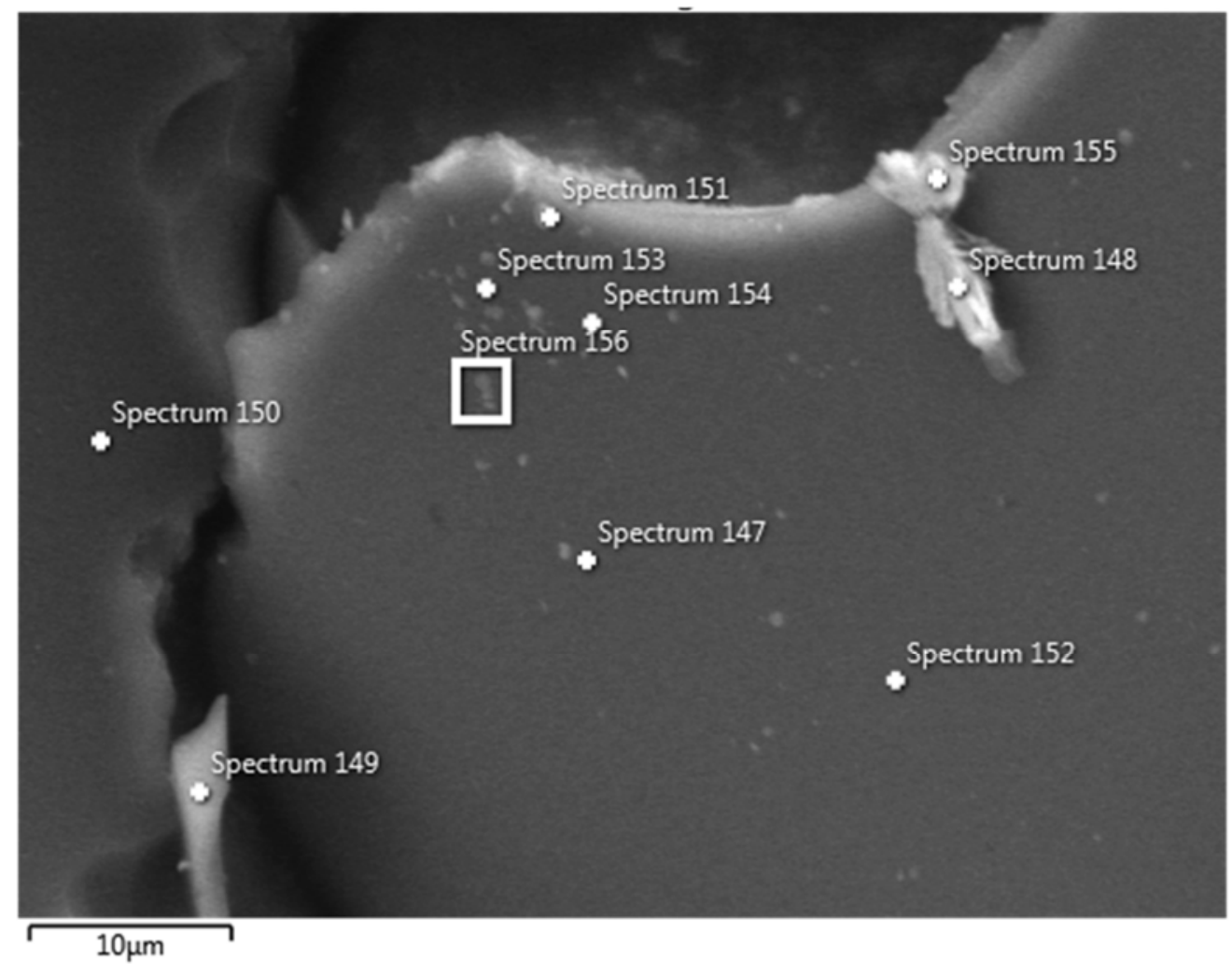

889

890

891

892

893

894

895

896

897 
898 Lahti et al. Figure captions

899 Figure 4. XRD diffraction pattern of Co/AC-catalysts.

900

901

902

903

904

905

906

907

908

909

910

911

912

913

914

915

916

917 


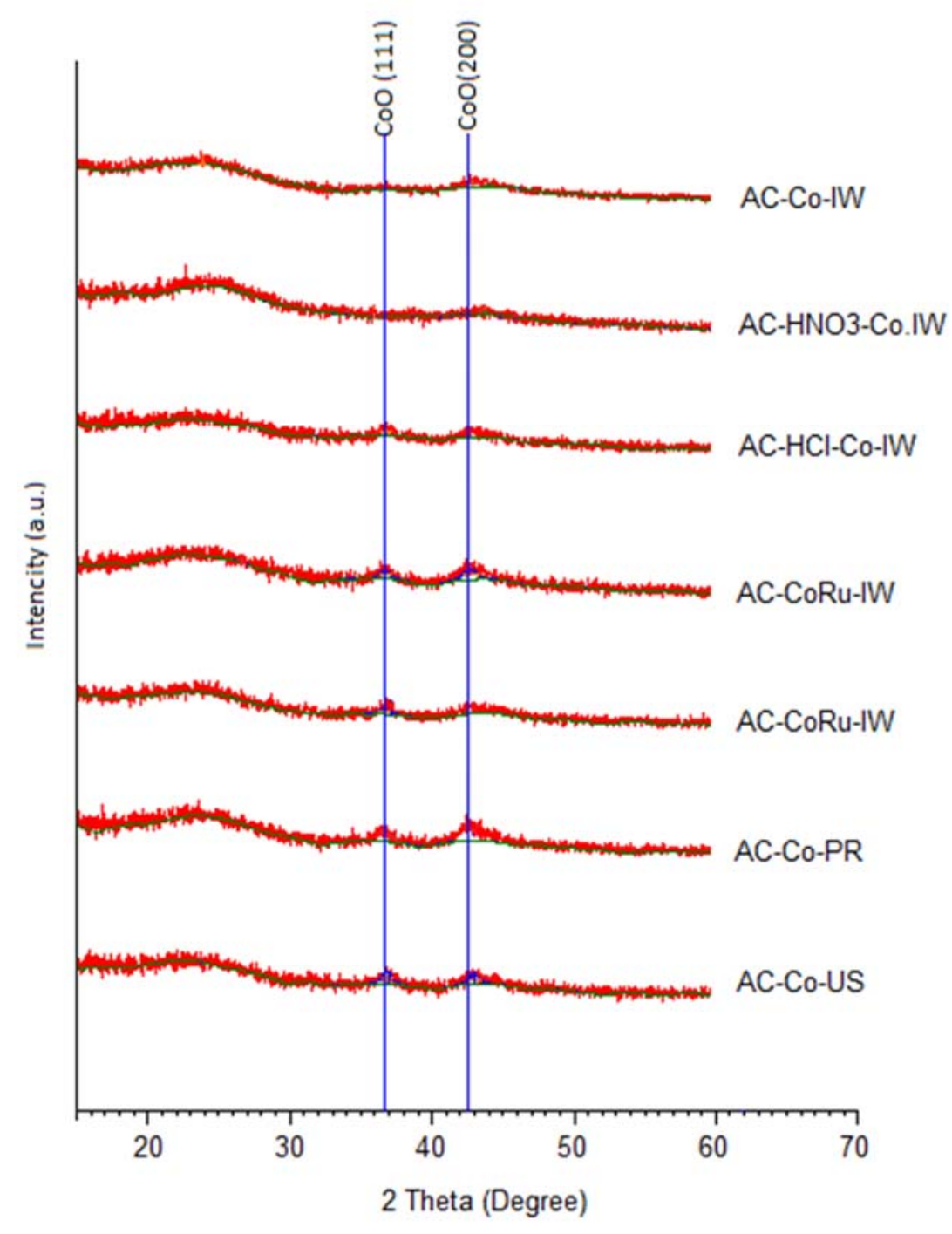

920

921

922

923

924 
Figure 5. $\mathrm{H}_{2}$-TPR profiles for $\mathrm{AC}$ supported and $\mathrm{SiO}_{2}$ supported Co-catalysts.

928

929

930

931

932

933

934

935

936

937

938

939

940

941

942

943

944

945 


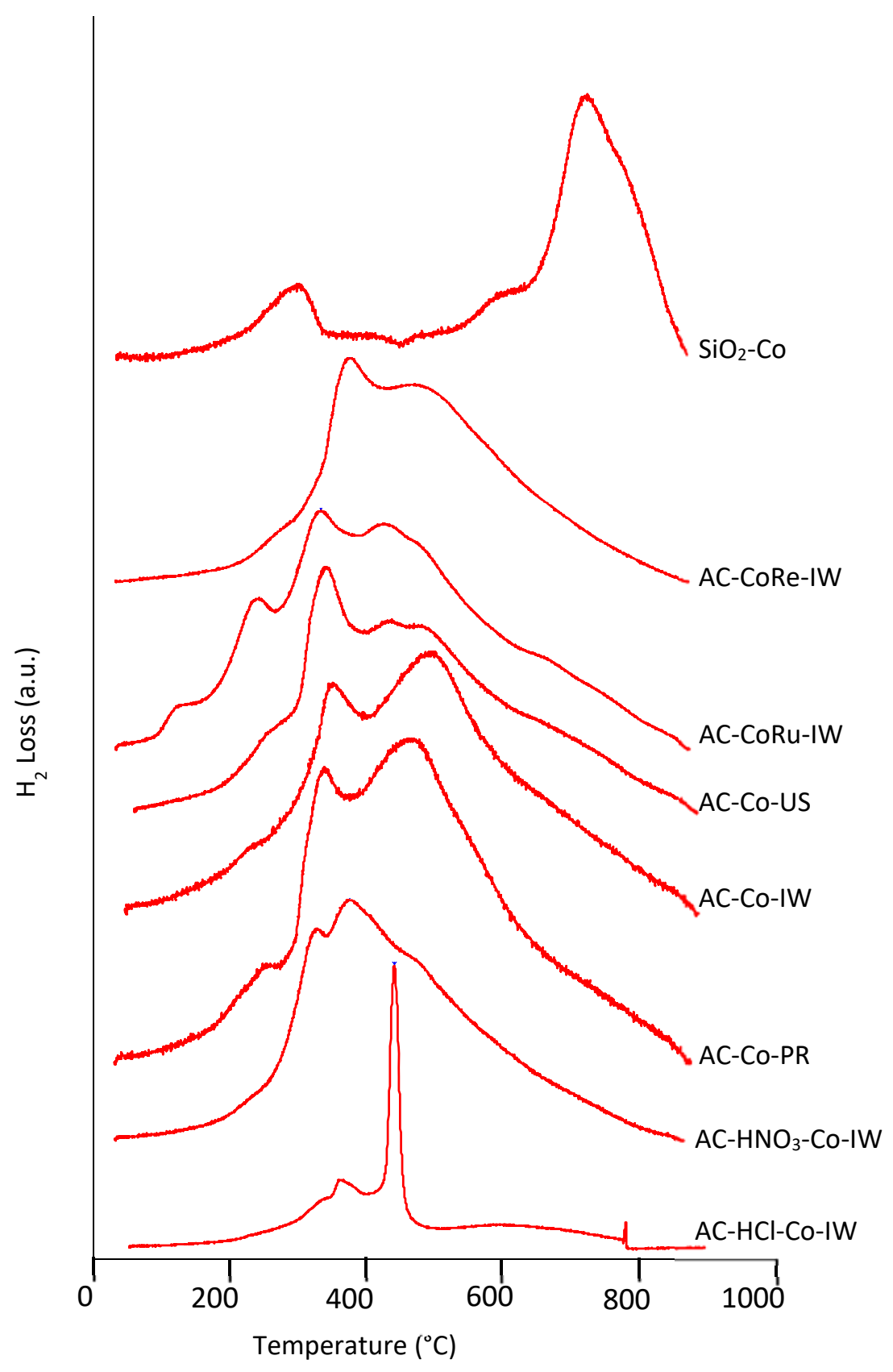

948

949

950 
951

952

953

954

955

956

957

958

959

960

961

962

963

964

965

966

967

968

969

970

Lahti et al. Figure captions

Figure 6. DRIFTs spectrum for commercial $\mathrm{AC}$, prepared $\mathrm{AC}$ and $\mathrm{AC}$ treated with $\mathrm{HNO}_{3}$. 


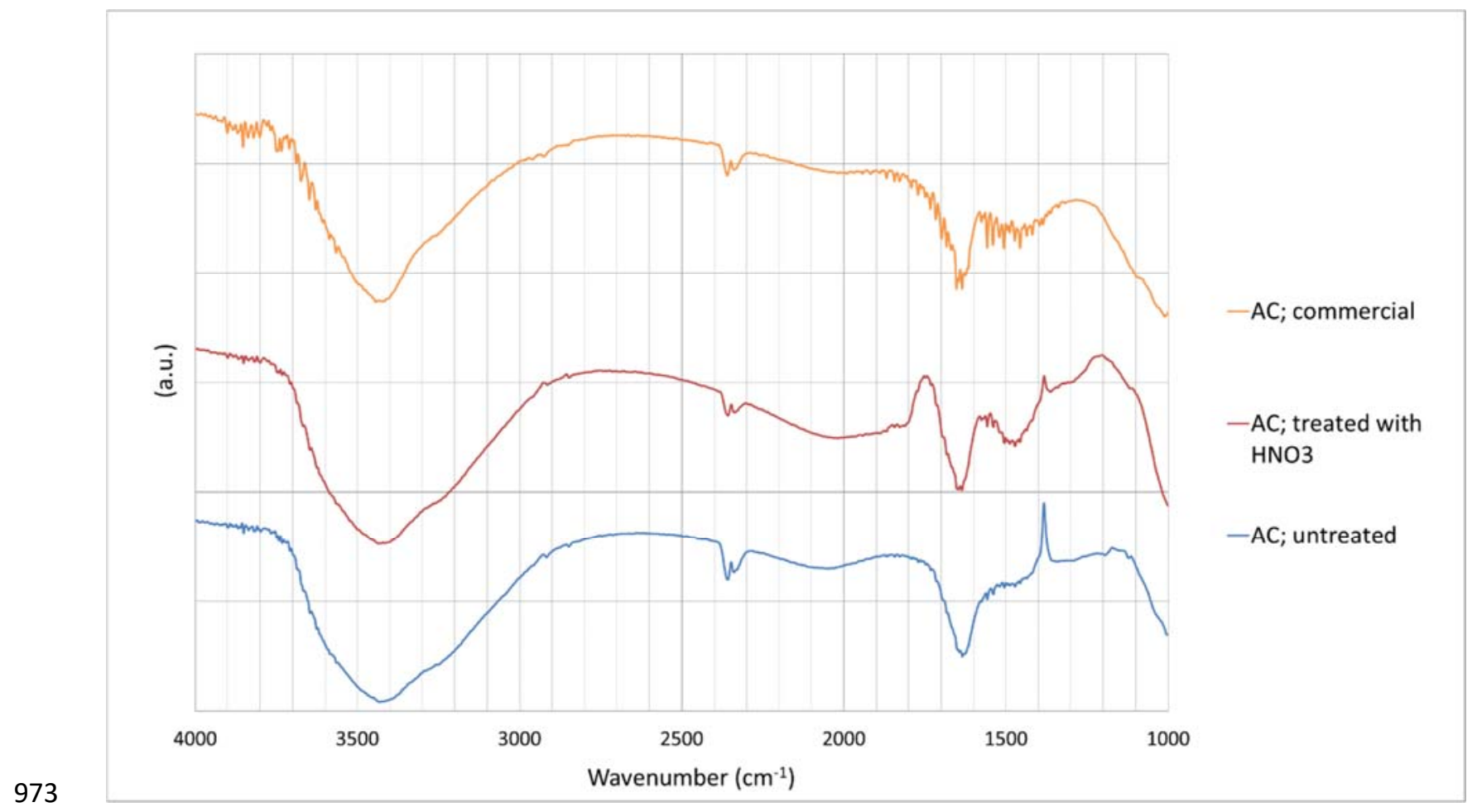

974

975

976

977

978

979

980

981

982 
983

984

985

986

987

988

989

990

991

992

993

994

995

996

997

998

999

1000

1001

1002

Lahti et al. Figure captions

Figure 7. High-resolution XPS spectrum of (a) C1s scans, (b) O1s scans, (c) Co2p-scans from Co/AC-catalysts. 
(a)

C1s Scan

15 Scans, $2 \mathrm{~m} 23.2 \mathrm{~s}, 900 \mu \mathrm{m}$, CAE $20.0,0.10 \mathrm{eV}$

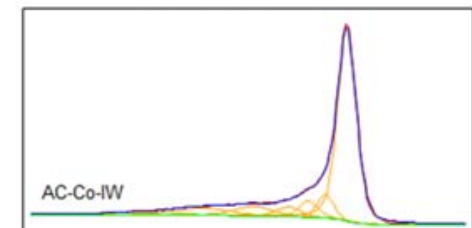

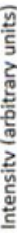

AC-HNO3-CO-IW

AC-HCl-Co-IW

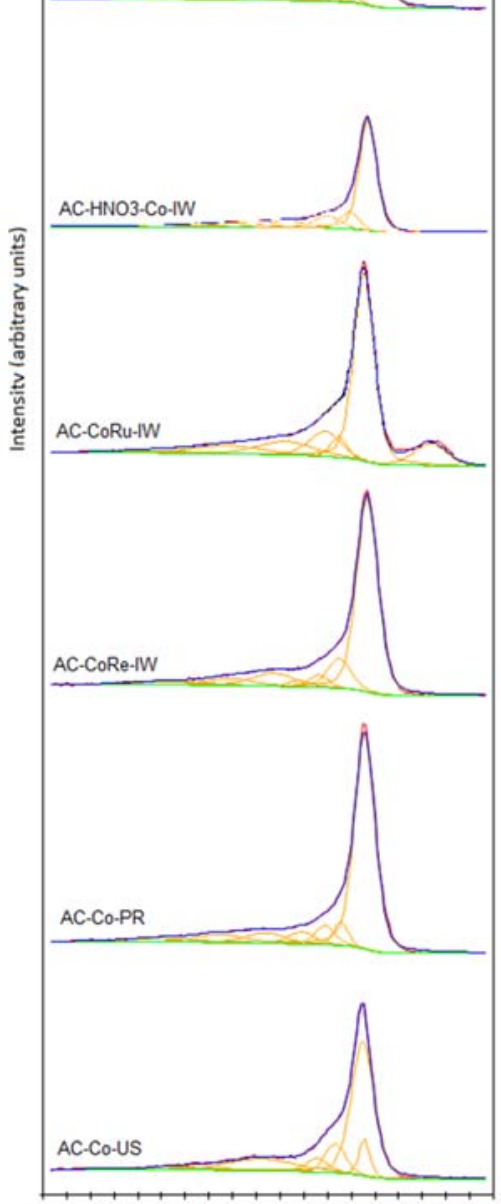

$\begin{array}{llllllllll}298 & 296 & 294 & 292 & 290 & 288 & 286 & 284 & 282 & 280\end{array}$ Binding Energy $(\mathrm{eV})$ (b)

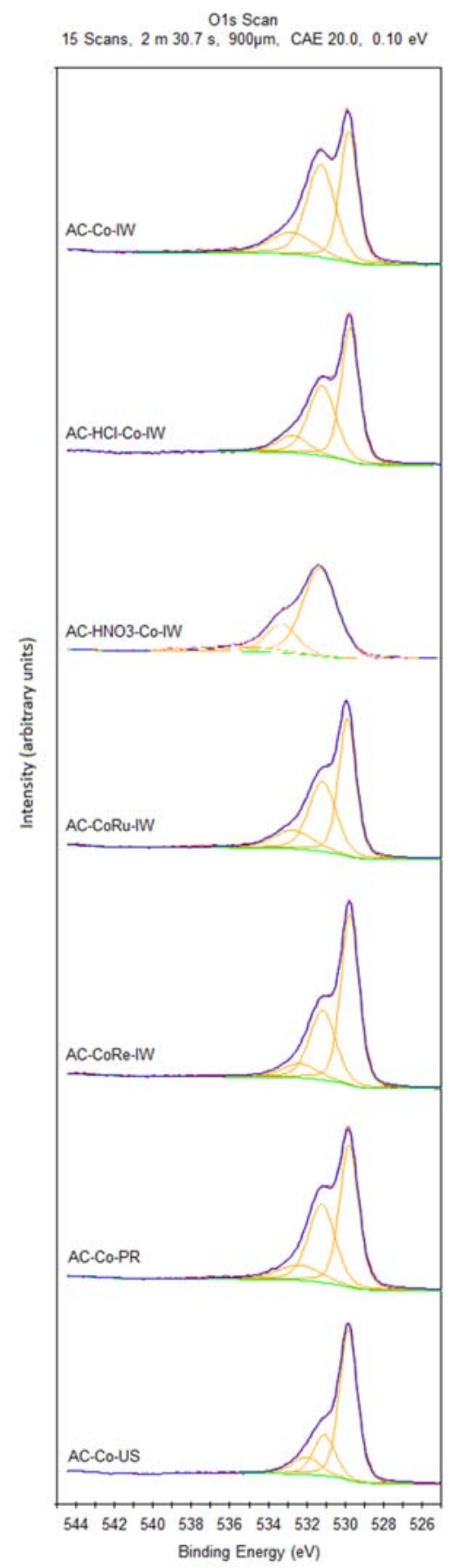

(c)

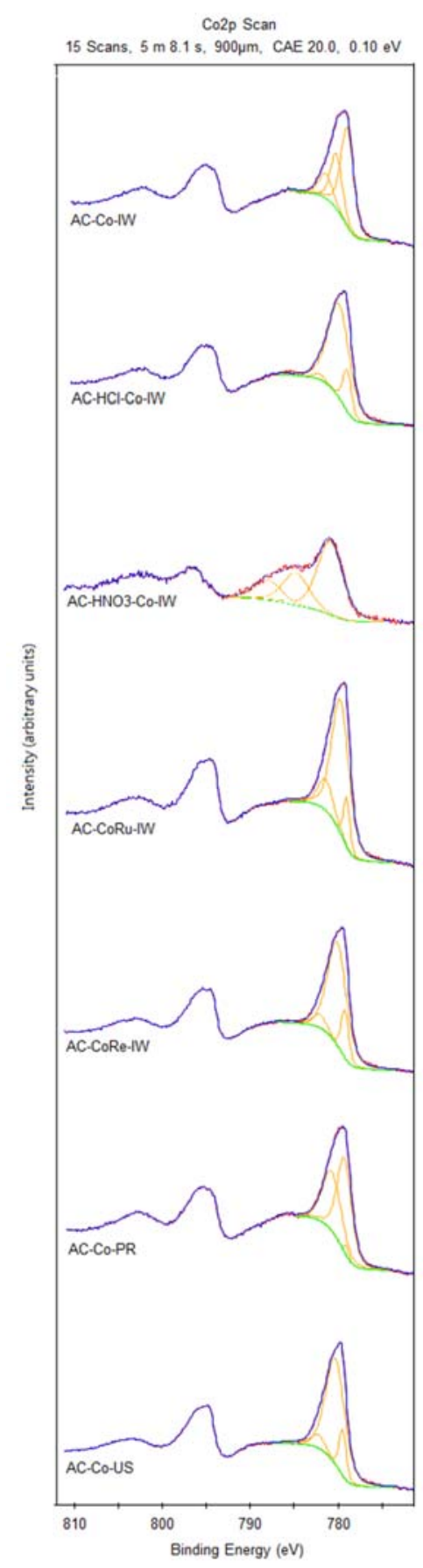

1005 
1007

1008

1009

1010

1011

1012

1013

1014

1015

1016

1017

1018

1019

1020

1021

1022

1023

1024

1025

1026

1027

1028

1029

1030

1031

1032

1033

1034

1035

1036

1037
Lahti et al. Figure captions

Figure 8. Functional groups on carbon surface from C1s, O1s, and Co2p-scans. 


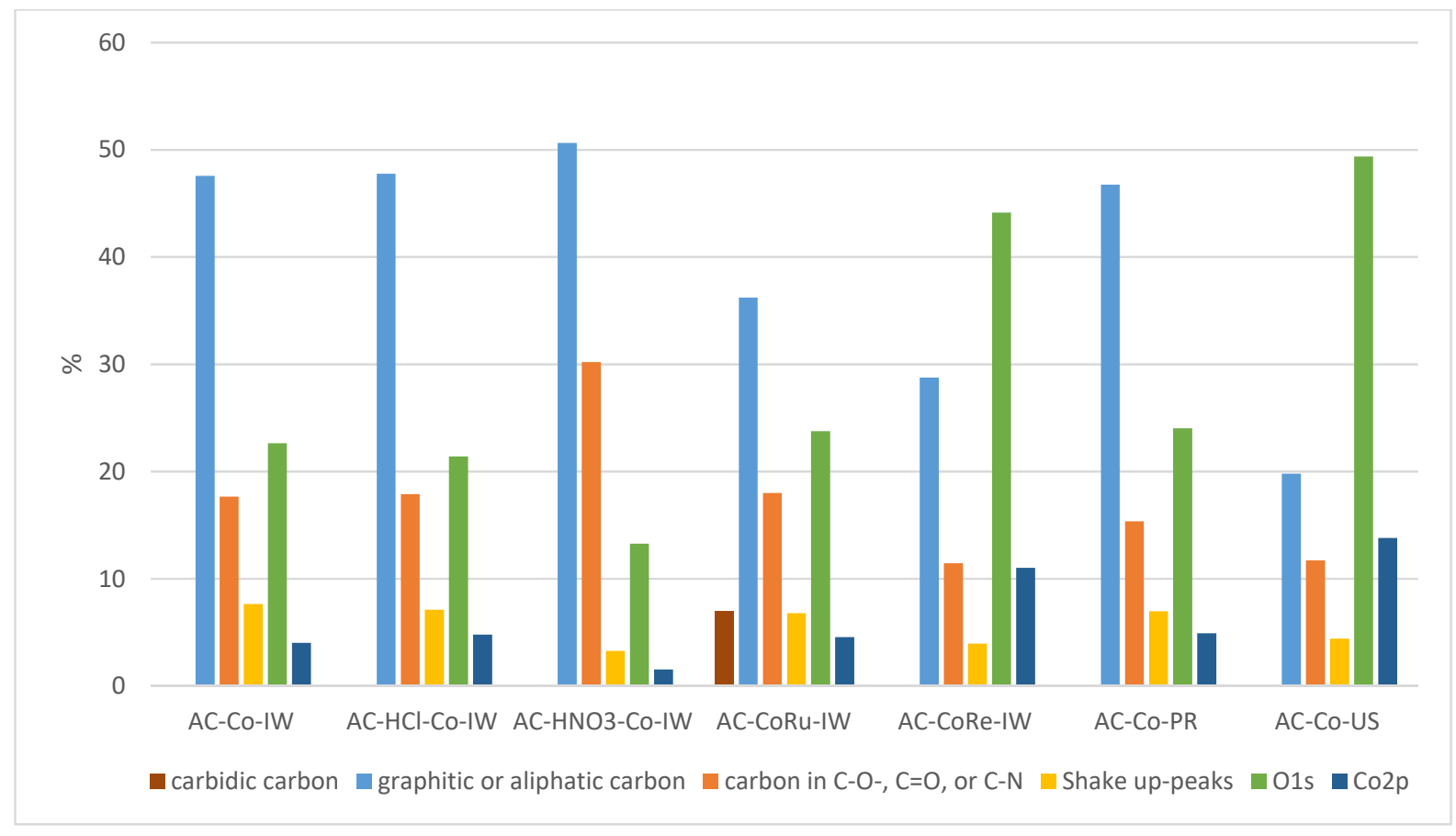

1042

1043

1044

1045

1046

1047

1048

1049

1050 
1051

1052

1053

1054

1055

\section{Referees}

Professor Edd Anders Blekkan, edd.a.blekkan@ntnu.no

Professor Harry Bitter, j.h.bitter@uu.nl

Kari Cook, kari@cookengineer.com 